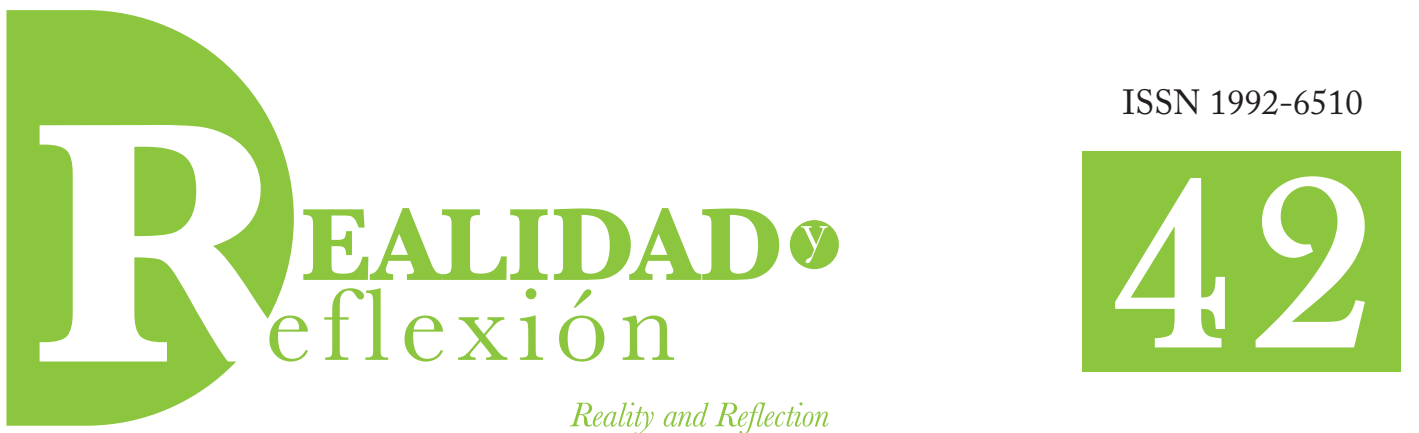

Año 15, N 42, San Salvador, El Salvador, Centroamérica. Revista Semestral Julio-Diciembre 2015

Year 15, No 42, San Salvador, El Salvador, Central America. Semestral Journal July-December 2015

\title{
Jaime Suárez Quemain, una vida truncada
}

\author{
Jaime Suarez Quemain, a truncated life
}

\author{
Eduardo Salvador Cárcamo \\ Escritor y bibliotecólogo, Universidad de El Salvador \\ Investigador literario, especialmente sobre la obra del poeta Roque Dalton.
}

\section{RESUMEN}

Jaime Suárez Quemain, fue un poeta joven que perteneció a la generación de La Cebolla Púrpura de los años 70, y colaborador de la revista La Masacuata, de tipo artesanal, de esa generación. Jaime fue un poeta maduro y con una visión poética destacable en el concierto de poetas contemporáneos de su tiempo. Relativamente poco se ha hablado o escrito sobre este malogrado bardo, cuya vida fue sesgada por sus ideales de libertad con democracia, y sobre todo por laborar en un semanario de izquierda, en esa época, que le costó la vida, sus ideales registrados en su obra poética, están vigentes como el poeta mismo, cuya poesía aún se encuentra $\tan$ fresca como su recuerdo.

Palabras clave: Poesía salvadoreña, biografía, ensayo.

\section{ABSTRACT}

Jaime Suarez Quemain was a young poet who belonged to the generation of Purple Onion 70, and contributor to the magazine Masacuata, artisanal, of that generation. Jaime was a mature and remarkable poetic vision in concert contemporary poets of his time poet. Relatively little has been said or written about this unfortunate bard, whose life was biased by its ideals of freedom with democracy, and especially for work in a weekly left, at that time, it cost him his life, his ideals registered in its poetry, are in effect the same as the poet, whose poetry is still as fresh as his memory.

Keywords: Salvadoran poetry, biography, essay. 


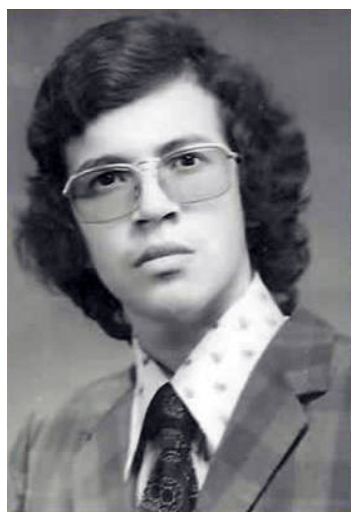

Jaime Suárez Quemain ${ }^{1}$

\section{Un fin de semana}

Un fin de semana, allá por 1972, en horas de la tarde, con el poeta Rigoberto Góngora visitamos a Jaime Suárez en su casa de habitación. El poeta residía en uno de los apartamentos, allí en la 5 de Noviembre. A las dos de la tarde, abrió la puerta amablemente su madre doña Carlota, pasándonos de inmediato a la sala. Allí se encontraba el maestro, escritor y poeta Luis Galindo, un tipo muy humilde y sencillo, amigo también de Góngora. La tarde transcurrió con charla sobre música, poesía, literatura, realidad nacional salvadoreña, educación, etc.

Jaime Américo Suárez Quemain era su nombre completo. Nació el 7 de mayo de 1949 (otras fuentes sostienen 1950 como su año de nacimiento; pero el mismo Jaime manifestaba ser del 50), en San Salvador. Sus padres don Alejandro de la Cruz Suárez Díaz, boxeador profesional, conocido como Álex C. Suárez, campeón de boxeo de El Salvador y el resto de Centroamérica, entre 1925 y 1927; su madre

1 Fuente: http://www.catalogo.catolica.edu.sv/cgi-bin/ koha/opac-detail.pl?biblionumber $=16844$ doña Francisca Carlota Quemaín de Suárez, Tenedora de Libros. Procrearon siete hijos, siendo Jaime el menor.

Jaime estudió su primaria en la escuela San Alfonso, y posteriormente se tituló de Contador, graduándose el año 1970 en el Instituto Superior de Enseñanza Comercial.

De acuerdo a notas aparecidas en blogger, como el titulado Turno del Ofendido, bajo la autoría de Mdiaz, he considerado algunas líneas, tales como estas:

Jaime creció lleno de amor y cariño, protegido por su madre, y hermanos, especialmente por sus hermanas Morena y Sonia, después de haber perdido a su padre a la corta edad de doce años. Doña Carlota describia a su bijo como un niño callado y solitario, que desde muy temprana edad mostró su pasión por la lectura. Asimismo contaba que cuando Jaime era un adolescente ella solía encontrar pequeños poemas, pero nunca le dio importancia, pues creía que era solo una faceta de su edad...

Seguramente este detalle haya hecho de Jaime un muchacho callado, solitario, retraído, inmerso en su propio mundo, de donde iría emergiendo su gusto por la lectura y por la poesía, relato que su madre describe en el párrafo citado, donde apunta que se encontraba con trozos de poemas, a los que restó importancia, por considerarlos cosas de su temprana edad. Obviamente no podía vislumbrar doña Carlota que en su hijo había un poeta nato, como se verá más adelante, cuando se analicen algunos de sus poemas. Volviendo con la charla de ese sábado, se destacó un aspecto muy particular relacionado con la música. 
Góngora mencionaba el gusto musical de Jaime, debido a la coincidencia con algunos de esos gustos musicales del poeta y de quien escribe estas líneas. Jaime Suárez era un fan de primera línea del cantante y actor norteamericano Elvis Presley. A raíz de esta particularidad, Góngora reiteró la invitación a su casa para departir con una tarde sabatina.

Jaime había comprado un álbum de cuatro discos LP (Long Playing) Vol. 1 de Elvis, con el cual le adjuntaron un póster con la imagen del cantante, de medio metro de alto, que tenía ubicado en su habitación. Desde luego que prestó dicho álbum con cierto recelo, pero confió, ya que Góngora también le garantizaba que iban a buenas manos y que se lo cuidaría como propio. Este detalle viene a colación por el hecho de que Jaime tenía una visión de mundo y manejaba una concepción revolucionaria dentro de su poética, y es aquí donde se deslinda la visión y el ser revolucionario con el mundo de la música, la cual carece de fronteras y de líneas políticas determinadas con etiquetas trilladas de derechista o izquierdista, en fin. Esto fue corroborado años después en el fragor de la guerra de los 12 años, ya histórica y famosa recorriendo el mundo, guerra que se llevó mucha gente de toda clase, que se llevó al poeta Rigoberto Góngora, destrozado por una mina.

\section{La tertulia y el lercer Lugar en el Segundo certamen 1970}

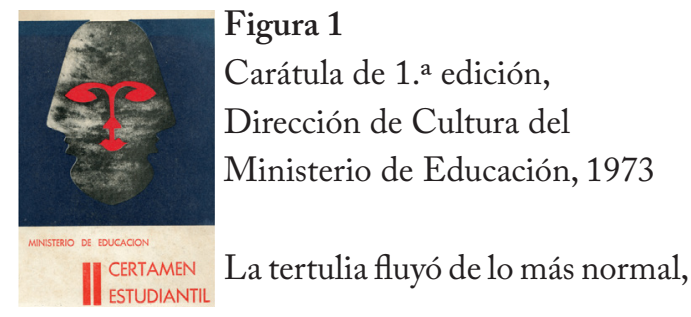

sencilla, y sin poses de intelectualismos, y surge una anécdota que quedó grabada en la memoria: se hablaba de escritores, poetas y artistas de diferente índole. Sostenía Jaime lo siguiente:

Viéndolo bien, si nos fijamos en los escritores $y$, poetas sobre todo, la mayoría son feos... bueno, me incluyo yo también... 'no'hombre', paja... pero es cierto. Por ejemplo, Quevedo, Lope de Vega, Allan Poe, John Keaks, Nicanor Parra, por citar algunos. Bueno, la mayoría de escritores somos feos. Si no, véanme a mi pues”... tal ocurrencia provocó una carcajada contagiosa. Se retomó la música. Jaime también tenía un gusto por el jazz entre otros géneros musicales. Este detalle musical y poético acrecentó la amistad entre los dos, aunque no bubiesen reuniones frecuentes, como lo hacian Góngora y Luis.

En sus poemas de ese entonces, se intuía el gran poeta que llegaría a ser. Había fuerza, madurez, sencillez y profundidad en la temática abordada, de manera llana y directa, pues ya venía de ganar un Certamen Estudiantil de Cultura, 1970, en la rama de Poesía, Cuento y Ensayo, auspiciado por el Ministerio de Educación, y el segundo en su orden. En el caso de Jaime, 2do. Lugar en la rama de poesía, los lugares quedaron así: 1er. Premio para la obra titulada "Un insomnio para no morir", calzado por Juan Pablo Martínez (del Colegio Superior de Comercio, Primer Año de Contador, San Miguel), 2do. Premio para la obra "Herida lágrima”, del autor Edgardo Alfonso Montoya Ibarra (5. ${ }^{\circ}$ Año de Bachillerato, Usulután), y el 3.er Premio para la obra: "Desde la crisis donde el canto llora", autor Jaime Suárez (Instituto Superior de Enseñanza Comercial, 3.er Año de Contador)... Los miembros del Jurado para este Certamen fueron Claudia Lars, Ricardo Bográn 
y David Escobar Galindo. Llama la atención la profesión de Jaime, equidistante de su vocación poética. Desde luego que lo uno no quita lo otro. Pero generalmente no compagina el oficio de Contador, en este caso, con la magia de las letras.

Se cita nuevamente este material registrado en el blogger Turno del Ofendido, lo siguiente, motivado por una entrevista que le hiciera a Jaime, el Profesor Luis Galindo el sábado 14 de agosto de 1971 en "Diario El Mundo", donde quedó registrada la auto descripción que Jaime se hiciera. Véase el fragmento de dicha auto descripción:

Creci cada segundo guardando manojitos de tiempo en los bolsillos, construyendo poemas con la mirada y escribiendo cuentos sobre el viento. Un día recogi un grupo de poemas, le llamé al conjunto "Desde la crisis donde el canto llora" y obtuve con ellos tercer premio del Segundo Certamen Estudiantil de Cultura; luego, obtuve un diploma en el que se me nombraba POETA JOVEN DEL AÑO (28 de mayo de 1971). Esto con base en una encuesta de Radio Continental, en el desaparecido programa "Pueblo Opina". Fundé la revista literaria "La Cebolla Púrpura". He participado en recitales en la capital y en el interior del país. He publicado cuento y poesía en algunos periódicos./... (in situ).

Jaime ya se había labrado su bagaje como poeta. Sobre todo por su edad, y más especialmente, en el ambiente hostil que rodea al mundo de las letras salvadoreñas. Como bien lo dijo: "Crecí guardando manojitos de tiempo en los bolsillos", expresión más que poética, destellos de un potencial que se veía venir, como se apunta líneas arriba. Luego, prosigue descifrando conceptos sobre su visión de la poesía, así:
"La poesía es un túnel. Dentro hay jeroglificos, insultos, variaciones, amor... preguntas y más preguntas...”.

"Interrogantes que queman... El poeta las toma, las ordena, imprime su yo, clava sus colmillos. Si lo bizo bien, es poesía; si no, aborto, sandeces...”.

"Estoy consciente de ser poeta, y mi amigo el tiempo me apadrina, ya gritarán y oirán los sordos".

"En un tiempo hacia poesía solo para mí. Me aburri de guardar inédita mi obra y sali del vientre de mi madre para mostrarla al mundo. Esa fue mi dicha mayor. Malos ratos no he tenido" (in situ en el blogger)...

Jaime manejaba un concepto de hacer poesía, de crear poesía, de escribir poesía, muy poco común, muy por fuera de los heterodoxos, esto es, siempre acotando su joven edad. El juego de imágenes corrobora esta aseveración, pues el registro entre líneas en que plasma Jaime la idea central de cómo manejar el verso, es su peculiaridad de ver el mundo y la realidad de su entorno.

Antes de mostrarles algunos de sus poemas, hay que saber un poco sobre su vida personal: contrae nupcias en 1975 con Thelma Cañas, de cuya unión nació su primer hijo: Alejandro Octavio Suárez Cañas, quien nació el 6 de octubre de ese mismo año. Tres años después, en 1978, se divorcia de Thelma, en septiembre, para mayor precisión. Pero en 1979 se vuelve a casar, esta vez con Sandra Yanira Morales Flores, quien le dio su segundo hijo: Jaime Enrique Suárez Morales, cuyo nacimiento se dio el 11 de agosto de ese mismo año. 
Jaime, como poeta, también ejerció el periodismo, y laboró para las siguientes instituciones: en el MINED, en la Agencia de Publicidad Lemus Simún, como creativo; luego se enrola como Jefe de Redacción del periódico "La Crónica del Pueblo", donde tuvo su última morada como trabajador, pues fue precisamente por trabajar en este periódico, calificado de Izquierdista, que lo señalaron con el dedo de la muerte. De acuerdo a este artículo que he estado citando, Jaime frecuentaba la Cafetería Bella Nápoles, y el viernes 11 julio de 1980, mientras departía un café con su amigo César Najarro, quien había laborado como fotógrafo para "La Crónica del Pueblo", llegaron unos personajes vestidos de civil, los rostros cubiertos (escuadroneros de la muerte, por su forma de operar), le tocaron el hombro a Jaime, lo esposaron y de una vez se llevaron a ambos. Se comentó con Rigoberto Góngora que si a Jaime lo habían secuestrado, difícilmente saldría con vida. Este comentario se hizo esa misma noche, porque según la noticia que había llegado, el secuestro fue realizado en horas de la tarde... y al día siguiente del secuestro, el 12 de julio, aparecieron los cadáveres de Jaime y César en las Lomas de San Francisco. $\mathrm{Su}$ asesinato fue bárbaro y cruel, con mucha saña, costumbre de esa época. Obviamente previo al asesinato, mucha gente del pueblo se movilizó, abogando por los dos periodistas, pero todo esfuerzo fue en vano, incluida las suplicas emitidas por la radio esa noche, que no dieron resultados. El cadáver de Jaime presentaba 13 lesiones en diversas partes de su cuerpo, producidas por arma cortante, de acuerdo al reconocimiento del médico forense.

Previo a su secuestro y posterior asesinato, Jaime se dedicaba a su trabajo y no estaba metido en ningún partido político opositor al Gobierno de facto de ese momento, por cuanto creyó que no se fijarían en su persona, y su inocencia en este particular no le previó que habían comenzado a perseguirlo. El periódico estaba ubicado cerca del Parque Centenario, y este parque, lamentablemente, desde esa época era considerado peligroso y de alto riesgo para el transeúnte común y sencillo del terruño salvadoreño. El periódico tampoco escapó de atentados fraguados por el enemigo, en su mente de seguro que albergaba el hecho de que lejos del partidismo o la partidocracia, podría tener la posibilidad de expresar la verdad de manera objetiva y sin preámbulos ni cortapizas, y sin temor a posibles represalias; pero en ese tiempo, esto era una utopía.

No se pueden cerrar estas líneas sin antes mencionar, que en noviembre de 1972, Góngora se va del país rumbo a Costa Rica, pero se queda en Managua unos días, siendo sorprendido por el terremoto del 22 de noviembre de ese año, y se topa con una Managua atada de manos... y al resto de Centroamérica... Góngora ayudó donde se lo permitieron las autoridades pertinentes, a remover escombros por ejemplo... obviamente, en el mes de julio, el recién entrado al gobierno salvadoreño como presidente, fue enganchado para que le diera un golpe bajo al "comunismo" representado, según ellos, por la Universidad Nacional (UES), y este hecho, desbarajusto a muchos estudiantes, de los cuales algunos tuvieron la oportunidad y la ayuda de emigrar a Guatemala, México y al resto de Centroamérica, tanto obligados, como uno que otro voluntariamente. Aquello fue un desastre, como lo serían las consecuencias provocadas por el terremoto citado. 
A propósito de Rigoberto Góngora, como de Luis Galindo, ambos fallecieron de manera distinta. Góngora fue despedazado por una mina en el fragor de la guerra, y Luis falleció en San Salvador por causas naturales, algunos años después, y fue sepultado en Sonsonate.

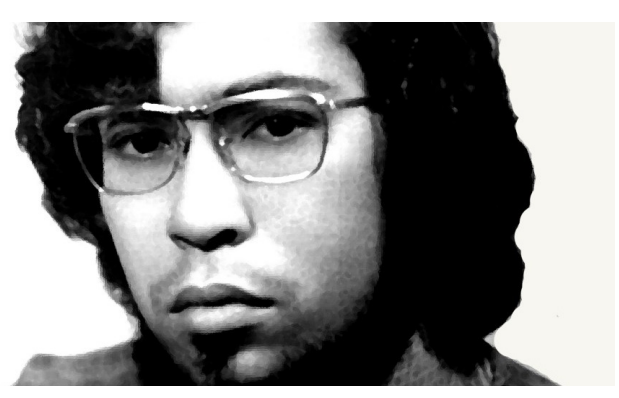

Jaime Suárez Quemain²

\section{Muestras poéticas de Jaime Suárez}

Para no extenderse más de la cuenta, hay que considerar el comentario de algunos fragmentos de cada poema, incluido en esta semblanza, sobre el poeta Suárez, e igual citaré un par de opiniones que vertieron en su momento dos poetas reconocidos como José Roberto Cea y David Escobar Galindo, quien además fue jurado del II Certamen Estudiantil MINED, donde Suárez ganara el 3.er Lugar con la obra ya mencionada, y de la cual se ha incluido solamente el poema titulado Prefacio.

En el poema "Los dictadores", Jaime sostiene que los dictadores son personajes o "señores que deambulan entre sombras/y en horas nocturnas ingresan como acólitos en/ ceremonias donde oficiantes de negro celebran horrendos/ ritos en contra del hombre/ usted sabe, señor/ que ellos podrían cambiar la religión"/... Esta manera peculiar en que Jaime le apunta a los tiranos, obedece al momento histórico salvadoreño, porque era una época de un El Salvador prácticamente militarizado y con el agregado de los escuadroneros y los grupos paramilitares, quienes no escatimaban atentar contra cualquier ciudadano que no comulgara con el oficialismo de siempre, por cuanto el poeta los considera que son una mezcla de militarismo y religión, es decir, se disfrazaban de corderos, pero vestidos de negro, como de luto anticipado, en fin. La noche siempre fue la mejor cómplice para desaparecer, asesinar y ejecutar los actos y actividades que sus mentes torcidas les dictasen a los subalternos ejecutores de los deseos malsanos de aquellos.

Porque si eran capaces hasta de cambiar la religión (la de ellos, al menos), entonces qué no podría esperarse del pueblo salvadoreño... Jaime es muy directo con estos versos al desnudar esa realidad con contundencia y de manera práctica, porque atreverse en ese tiempo a plasmar y publicar este tipo de poemas en el fragor de una guerra popular prolongada, era casi como un suicidio anunciado.

Este poema descarnado recoge no solo el sentir del poeta, que sin considerarse político ni pregonar ser izquierdista, era más comunista que muchos comunistas de cepa... Hace, pues, un retrato muy bien logrado de los dictadores de esa época y no sólo de origen salvadoreño si no del resto de América Latina. 


\section{Los dictadores}

...los dictadores, señor, deambulan entre sombras

$y$ en horas nocturnas ingresan como acólitos en

ceremonias donde oficiantes de negro celebran

borrendos

ritos en contra del hombre

usted sabe, señor

que ellos podrian

cambiar la religión,

De indumentaria.

Opero usted los convierte

en guardianes de su estómago,

les compra rifles

y juegan a la guerra

y luego usted, señor,

usted los condecora

y orgullosos caminan sacando

el pecho que está lleno

por dentro de alacranes

y usted los aplaude

$y$ usted los elogia

y goza con el clima de tranquilidad,

de muertos en los ríos,

de secuestros, de torturas,

de bombas y de sangre.

y usted los premia

permitiéndoles sentarse a su mesa

y que entren a sus clubes

y se casen con su prima lejana

educada en europa

y les pasa sus vicios

y ahora juegan bridge

y beben whisky

$y$ manejan un mercedes.

los dictadores, señor,

olvidan que nacieron

en medio de un arroyo

$y$ disparan en contra del arroyo $y$ pretenden sacar aquel arroyo,

basta que un dia

el arroyo es un mar

en el que mueren podridos:

Usted y los tiranos.

En este otro poema Jaime sostiene prácticamente un soliloquio y además habla con todos, piensa en voz alta y en silencio, a fin de que su disparo, realmente resulte siempre colectivo y "Porque me quema a veces la nostalgia,/ el asombro en la voz, el pase en corto,/ las perras ganas de aguantar a los fantasmas/ que me comen el alma a dentelladas,/ mientras se escucha en el café/ una melodía tristona -siempre son tristes/ si es en el café donde se escuchan--/ y yo me desangro inútilmente,/ a borbotones pero inútilmente"/...

Se puede notar que al poeta lo invade la nostalgia, al punto de quemarle, mientras su voz asombrada cabalga en el pase corto de futbolista diestro para perderse en sus perras ganas de aguantarse de todos los fantasmas que lo asalten en un loco afán de comérselo con todo y alma, y aunque se sienta acompañado por una triste melodía, ello no evita que se desangre a borbotones de manera inútil; no se siente vencido, porque detrás de todo ello él se escapa por esas calles de dios, totalmente repleto de amor, que antepone a cualquier obstáculo que se le ponga enfrente, tales como diques, compuertas, muros invisibles plegados de avalanchas, cuyo contraste se estrella con la vida. Por eso el poeta se siente como ese disparo colectivo, que le permite luchar a campo traviesa para no caer vencido por la soledad y la vendimia del desconcierto que la vida misma le traza en su propio destino... sosteniendo que no podrá ser esclavo de los gritos de las modas, que su anarquismo le permite contrarrestar, porque 
aunque lo maldigan, él nació para soñar, sin importarle que hayan prohibido soñar, porque ello es sinónimo de libertad...

\section{Un disparo colectivo}

Porque me quema a veces la nostalgia, el asombro en la voz, el pase en corto, las perras ganas de aguantar a los fantasmas que me comen el alma a dentelladas, mientras se escucha en el café una melodia tristona-siempre son tristes si es en el café donde se escuchany yo me desangro inútilmente, a borbotones pero inútilmente, cuando de amor repleto me voy por esas calles de dios con papel tumbado por el viento y se oye el crujir, el alboroto de ese tiempo que se cae pese a todo y ya no bastan diques ni compuertas, ni muros que detengan la avalancha, porque los duendes ya no asustan a los niños y soy-aunque no quieran- un disparo colectivo, una pringa de luz en las tinieblas y porque -por más que me maldigannacípara soñar aunque el sueño de plano esté probibido y se acerquen los dichosos normales y me quieran cambiar mi canción, Cargarme con sus baterias y volverme imbécil que esté al tanto del último grito de la moda, $y$ del actual amante de doña fulanita o del mustang azul de don idiota, $y$ porque les molesta mi profunda vocación anarquista, mi sacrosanto amor por la desobediencia, y quieren caerme con sus palos, ponerme su disfraz
Y que baile la samba que ellos bailan, $y$ porque digo no, $y$ me vale un pito, y prefiero mis fantasmas o jugar con mi sombra. y mando al carajo a "los inspectores de herejias" que quieren registrarme, anularme el carnet, voltear mi cerebro y averiguar qué es lo que guardo, $y$ convertirme en ciudadano robot, clásico ejemplo de las buenas conciencias.

Este poema es bastante personal y de recuerdos y nostalgias para la vida del poeta. Un round a tu recuerdo, lleva al poeta a un abierto conversatorio con su querido padre, quien falleciera cuando Jaime apenas tenía 12 años de edad. En este conversatorio poético, se dirige a su padre, que se ganaba la vida practicando el pugilismo, siendo pues, campeón nacional de boxeo, citado líneas arriba, y que nunca quiso caminar con su estatura, porque lo consideró cuestión de orgullo, de ahí el hecho de que se haya tardado en escribir y entregarle este poema, considerándolo como un telegrama rezagado, porque "Se me vino a los ojos tu palabra,/ llena de la humildad/ que cubría el eco de tu nombre./ Vino así,/ No sé como,/ sin llamar a la puerta,/ Simplemente/ Tomó mi dolor entre sus brazos/ y me llevó hasta la vieja casa,/ al canapé donde solías hacer la siesta/ y fumabas tu tristeza."/... Sin duda, el poeta se sintió invadido por los recuerdos de su padre, de la nostalgia que le dejó su partida; pero en su mente continuaba vivo, de ahí que el mismo título sea la clave para descifrar el concepto poético de que no siempre se verá con eufemismo el sentimiento revolucionario del intimismo lírico del poeta. Si no, hay que ver los siguientes versos de este poema: "Las cosas han 
cambiado,/ Ya quedó atrás el muchachito/ Que contempló tu muerte,/ La vida me hace madurar a bofetadas."/... Como que le surge un hato de rebeldía, de esa que a todo hijo le contagia para considerarse dueño del mundo. Le argumenta a su padre: Hoy las cosas han cambiado, y en efecto, media una gran distancia entre la partida de su padre y su actualidad. Posiblemente en el poeta aflora todo aquello que no pudo ser posible: compartir con su padre, como jugar pelota, recibir o pedirle un consejo, salir de paseo, en fin, y ello marcaría a Jaime hasta su propia muerte, que no fue su muerte... y cierra el poeta con este lapidario grito: "Cuando estoy tan solteramente solo/ Y me urge hablar con alguien/ Se me viene a los ojos tu palabra”... Como que los vasos comunicantes son como un lazo, más fuerte que el propio sentimiento que une a padre e hijo, o a madre e hijo...

\section{Un round a tu recuerdo}

A Álex Suárez

Siempre me opuse a caminar

Con tu estatura

En el ojal de la camisa

-Siempre cuestión de orgullo-

De alli proviene el hecho

De entregarte tan tarde este poema,

Por lo que pasa a ser

Algo así como un telegrama rezagado.

La verdad

Es que de momento

Se me vino a los ojos tu palabra,

Llena de la humildad

Que cubría el eco de tu nombre.

Vino asi,

No sé cómo,

Sin llamar a la puerta,

\section{Simplemente}

Tomó mi dolor entre sus brazos

Y me llevó hasta la vieja casa, Al canapé donde solias hacer la siesta

$Y$ fumabas tu tristeza.

Eran los días.

En que clinchabas tu presencia

Con el rostro de un niño que tenía

Doce años jugando entre tus manos,

$Y$ contabas tus hazañas en el ring del mundial

Cuando el boxeo era boxeo

$Y$ no una exbibición amanerada.

Ahora, viejo,

Las cosas han cambiado,

Ya quedó atrás el muchachito

Que contempló tu muerte,

La vida me hace madurar a bofetadas.

Pero no creas

Que doy con los dientes en el polvo,

Como tú

Pienso que es permitido doblarse

Pero no partirse.

$Y$ abi voy, caminando,

Flirteándole a la vida su amargura,

Cuidándome de los golpes a los bajos,

Tratando

De terminar en pie este largo round.

Aunque a veces te confieso,

He llegado a flaquear, a quedar groggy

$Y$ querer tramitar un suicidio voluntario.

Pero basta un vistazo a tu retrato

Y ya no hay vuelta de hoja,

Sé que dejaste tu punch sobre mi verso,

Yjab a jab

Iré elevando mi nombre hasta tu nombre.

Viejo,

Tengo una deuda contigo,

Me querias ingeniero,

$Y$ te sali poeta, 
Pero no es cosa de ir por ahi

Soportando un disfraz que desentona.

Contigo pasó lo mismo,

Te querian curita

Y saliste campeón de box ;Y qué campeón, carajo!

"Perdona que te quite tu tiempo"

Pero a veces

Cuando estoy tan solteramente solo

$Y$ me urge hablar con alguien

Se me viene a los ojos tu palabra...

Este poema de breve descripción íntima, trae a la memoria el poema de José María Cuéllar (cuya muerte quedó envuelta en un misterio): Acabo de partir de mí mismo, también con una descripción personal e íntima, diferente en su contenido, pero parecidos en su esencia. Dice así Jaime: "Un día moriré, no cabe duda./ Marcharé con mis trapos a otra parte."/... Versos premonitorios de todo buen poeta, que de alguna manera anuncian su muerte no declarada, como lo hizo en su momento el poeta uruguayo Javier Heraud, y Leonel Rugamas en Nicaragua, poetas que murieron jóvenes, que no alcanzaron ni los 21 años siquiera. Jaime se empeña en mostrar ese camino espinoso que es una realidad irreversible: mirarle a la muerte cara a cara, muy de frente... y prosigue el poeta: "Un soneto tal vez fechado en Marte,/ Dirá que estuve: fui poesía cruda./ Por mis huellas sabrán que sin ayuda,/ Sin un mínimo gesto/ y sin alarde,/ De un sorbo me bebí toda la tarde/ Y mi lengua jamás se quedó muda."/... El poeta está consciente de su poesía, la cual es descarnada y cruda, según su propia visión, aunque Escobar Galindo diga que "Su poesía es directa, punzante, sin mucha elaboración, ni interior ni formal. Se salva por la fuerza y la sinceridad. Temperamento de signo anarquista, según lo dejó traslucir en muchos poemas."/... Con relación a "sin mucha elaboración", se ha de entender no acabada, no pulida, no peinada y con baño de aderezos, pues ese detalle precisamente, es lo que hace a la poesía de Jaime un eslabón directo, tal como su "Disparo Colectivo", porque va limpio y desnudo, justo al blanco, es decir, a la conciencia de los que aún se encontraban en dulce letargo frente a su propia realidad. Ahora lo que dice el Pichón Cea: "Jaime era poeta antes de ser periodista, pero antes de ser poeta era un hombre preocupado por el destino de su pueblo(...) En cuanto a su labor poética, se dice que estaba en ese período de afirmación, en ese período de aprendizaje(...) de ahí que muchos de sus textos dejen un sabor de no concluidos(...) pero sí tienen la combustión del hombre que es poeta y sabe que tiene que decir su mensaje, lanzar su voz, dejar su testimonio de un tiempo duro y amargo..."/...

Son dos posiciones que se acercan y se distancian, esto es que uno sostiene que los poemas de Jaime no eran muy elaborados, y el otro dice que dejan un sabor de no concluidos; por cuanto propongo que usted, amable y estimado lector, juzgue estas opiniones, incluida la mía, que va de esta manera: La poesía de Jaime era espontánea, directa, desnuda y 'descarnada', sin adornos ni aderezos, lo cual se debía al potencial poético nato en él, y por ello el título de este trabajo: Jaime Suárez Quemain: Una vida truncada, esto es, que truncaron al poeta, al creador, al poeta visionario, que sin saberlo, supo que su vida no llegaría muy lejos, pues apenas llegó a los 31 años de edad, cuando los sicarios se encargaron de sesgarle la vida, porque un potencial enemigo del sistema y su poesía podía tomar mayor fuerza de la que ya tenía y no fuera a ser el tuerce, que hubiese provocado más de un golpe de Estado, o alguna huelga de brazos caídos, sutil manera de derrocar 
una dictadura. Hizo honor a su propio canto, y para que usted también, querido lector estime externar nuevas opiniones, lo dejo con este poema, para que asimismo, eleve su propio canto...

\section{Canto a mí mismo}

Un dia moriré, no cabe duda.

Marcharé con mis trapos a otra parte.

Un soneto tal vez fechado en Marte,

Dirá que estuve: fui poesía cruda.

Por mis huellas sabrán que sin ayuda,

Sin un minimo gesto y sin alarde,

De un sorbo me bebi toda la tarde

Y mi lengua jamás se quedó muda.

Solitario quizá, no pesimista,

Un poco soñador, serio, cansado,

Con una buena dosis de anarquista:

Dirán mis biógrafos austeramente.

Amó con furia, no lloro el pasado

$Y$ se fue de este mundo simplemente.

\section{Figura 2}

Jaime Suárez Quemaín: Biografía de un Anarquista salvadoreño

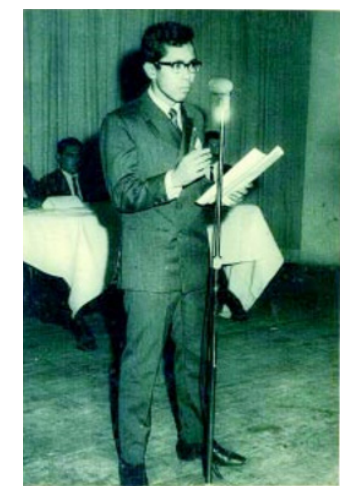

3 http://esperanzaslibertarias.blogspot.com/2015/07/jaimesuarez-quemain-biografia-de-un.html
Para el cierre de estas líneas se retoma un poco del poema "Prefacio", con el que abre el poemario ganador del tercer lugar en el Certamen Estudiantil de Cultura, ya mencionado. Siempre sutil y potente voz, cantando desde su propio yo colectivo. Inicia Jaime con desgarrador recuerdo: "Desde la inocencia/ en que pecó mi vida/ hasta el sacramental dolor de mi palabra;/ agólpanse los meses y los días,/ que enjugan el anillo,/ de la fuerza corrosiva que me impele."/... Aquí el tiempo es el tema "dilema", porque el poeta como que siente que el tiempo va amarrado a la vida y todavía hay mucho por hacer y quién sabe que la vida alcance, porque el tiempo sigue ahí, incólume e indeleble, como la tinta electorera que se mira y no se mira, en fin... y continua: "Es mi forma de morir/ metido en una letra,/ entre raptos donde el germen se fermenta/ o la duda/ encadena hasta las equis"/... el tema de la muerte en cierto modo, es recurrente en el poeta, que a su vez destella que el conocimiento y la cultura siempre irán reñidas a nuestras vidas, porque sentirse metido en una letra y terminar compungido y hasta encadenado como las equis, es bien jodido... y quiero terminar citando un par de fragmentos más de este poema; pero saltándome alguno de ellos en su conjunto: "Es mi ideal/ El que les ofrezco a gritos./ Ese furioso impulso/ De no ver la íntegra/ Servidumbre de las leyes;/ El ungüento de las horas/ Que me exige un milagro;"/... aquí el poeta se vuelve un tanto intimista, pero con fuerte voz para impulsar el grito que sacuda a esa servidumbre disfrazada de leyes que por antonomasia duermen el sueño de los justos... y se cierra con lo siguiente: "Este es mi testimonio./ Lo escribí desde la crisis/ Donde el canto llora"/... Con este final, el poeta como que estaba heredando muy anticipadamente su poesía, cuando afirma: 
"Este es mi testimonio surgido de la crisis donde el canto llora", como quien dice: "les dejo mi palabra, les dejo mi recuerdo, les dejo mi trabajo poético y su mensaje".

Será usted, lector amigo, quien considere si continúa vivo después de mi muerte, o si muere sin mí, aun no habiendo muerto.

\section{Prefacio}

\section{Desde la inocencia}

Hasta el sacramental dolor de mi palabra;

Agólpanse los meses y los días,

Que enjugan el anillo,

De la fuerza corrosiva que me impele.

Es mi forma de morir

Metido en una letra.

Entre raptos donde el germen se fermenta

O la duda

Encadena hasta las equis.

Es mi ideal

El que les ofrezco a gritos.

Ese furioso impulso

De no ver la integra

Servidumbre de las leyes;

El ungüento de las horas

Que me exige un milagro;

Este ver y no oir

Conque me leen;

Este llorar con inventado llanto

Porque hasta eso se acaba de repente

Es esto lo que veo;

Un museo de estatuas

Que ambicionan

Ser protagonistas,
Meterse en un libro,

Encontrar una moneda de oro

En el sin-prestigio de su misma hambre

$Y$ marchar alegres

Con una sonrisa memorable entre las cejas

Este es mi testimonio.

Lo escribi desde la crisis

Donde el canto llora (pps.73-75)

Nota:

Posiblemente, Jaime Suárez escribió estos poemas entre 1968 y 1971.

\section{Corolario}

El poema de Chema Cuéllar, es en diferente cuanto a que no es en sí un canto a sí mismo, sino más bien, una manera de desmarcarse del mundo y su realidad, es el sentirse solo y absoluto, sin necesidades, pues soy "autosuficiente" les guste o no, porque me basto a mí mismo para salir adelante; obviamente, esto es una alegoría de Chema con sabor a negación velada y una confesión de que recién acaba de dejar este mundo, es su manera intencional, dentro del contexto poético, dentro de un juego de palabras para despertar la conciencia del yo interno que llevamos cargando desde el mismo segundo en que nacemos... pero le dejo, amable lector, también con este poema de Chema Cuéllar: Acabo de partir de mí mismo, para que descifre por sí mismo, los elementos que discurren entre el poema Canto a mí Mismo de Jaime, con el que a continuación será su rúbrica para un pensamiento reflexivo. 


\section{Acabo de partir de mi mismo}

no soi chema cuellar

ny soi amigo de nadie

ny tuve una abuela paralitica

ny soi poeta

ny ciudadano

ny nada

me vale un pyto que nadie se acuerde de my

me llevo a san salvador en el volsillo

$i$ hablo con gentes

que no se conocen

ni me conocen

no importa si una puerta se cierra en nicaragua

si una muchacha se declara en santiago

sy una paloma vuela por el yan-se

si el mejor libro se está escribiendo en lima

no me importa

estoi vacio

solitario como un abrigo de invierno.

José María Cuéllar

\section{Referencias}

*Prefacio tomado de: Desde La Crisis Donde El Canto Llora (Tercer Lugar en el Segundo Certamen Estudiantil de Cultura, 1970 Ministerio de Educación)

http://www.artepoetica.net/Jaime_Suarez.htm http://turnodelofendido.blogspot.com/2008/08/ biografia-de-jaime-surez-queman.html

Publicado por Néstor Martínez en http://www. universo-cultural.com/colaboradores/166-jaime-suarez-quemain-una-vida-truncada Miércoles, 16 septiembre 2015.

Y en Trazos Culturales, Diario Co Latino, números 2089-2091. Miércoles 7 y Jueves 8 de enero de 2015, páginas 16-17; página 14 (Nota: publicación incompleta).

Segundo Certamen Estudiantil de Cultura, 1970 : poesía, cuento, ensayo Tipo: Libro Series:

Ciudad de Santa Tecla. Certamen Estudiantil de Cultura 1.Editor:

30/01/2014. San Salvador Ministerio de Educación 1973, Edición: 1. ${ }^{a}$ Edición. Descripción: 239 p. 20 cm.Tema(s): Literatura salvadoreña. 